\title{
The Profession
}

\section{The American Political Science Review Hall of Fame: Assessments and Implications for an Evolving Discipline}

\author{
Arthur H. Miller, Charles Tien, and Andrew A. Peebler, The University of Iowa
}

Now that baseball has returned as a cherished American pastime, although with a tarnished image from the 1994-95 strike, one can again invoke the "Hall of Fame" concept for outstanding performance. Induction into the Baseball Hall of Fame is a matter of politics (witness the controversy surrounding the Pete Rose exclusion). Clearly, despite baseball's heavy emphasis on statistical records of performance, other criteria besides hard numbers are invoked for admission.

No doubt politics would also enter into selecting individuals for a Political Science Hall of Fame. We hope to avoid some of these politics by narrowing our scope to an American Political Science Review (APSR) Hall of Fame. Who would comprise the Political Science Hall of Fame if the criterion for induction was the number of publications in the APSR? How would the APSR Hall of Fame compare to the roster that would result if other measures of visibility and performance, such as the frequency of citations, were employed?

\section{Why an Interest in Who Publishes in APSR?}

APSR is the leading political science journal in the United States (for an authoritative report on journal rankings, see Garand 1990).

$A P S R$ is substantively broad based, peer reviewed, high quality, widely circulated (16,000 subscriptions), and has an acceptance rate of about $10 \%$. An article published in $A P S R$ indicates research of considerable merit and significance for the entire field of political science. Given the prestige and difficulty associated with publishing in $A P S R$, we argue that accomplishing this task a number of times is a feat that should be recognized.

Others might argue that one's curiosity regarding who published in $A P S R$ and how frequently is a reflection of our basic human desire for drawing comparisons. Festinger (1954), among others (e.g., Tajfel 1981), suggests that there is a basic human drive to evaluate one's own opinions and abilities, and that this evaluation inevitably involves comparisons with others. In short, we are all curious to know who has published most frequently in APSR.

Information on the frequency of publishing in $A P S R$ provides another means of ranking the scholarly production of political scientists and political science departments. Biographical information on those who publish most frequently in APSR (such as where they received their Ph.D.), as well as information on where those individuals are currently teaching, would provide considerable insight into the strength of different graduate programs around the country. Previously, such rankings of individual scholars and departments have used a variety of approaches. For example, some have employed reputational rankings determined through surveys of department chairs. Others have used publication record (i.e., the number of publications of various types) or the number of citations (the citation index) to each individual's work.

Each of these approaches for indicating individual or department standing in the discipline has some limitation (for an in-depth critique see Klingemann et al. 1989). Reputation may have little to do with an individual's actual contribution to the field or outstanding academic performance. The relative importance of various journals, and books compared to journals, is difficult to determine when employing the "publication record" for ranking individuals in the discipline. The citation index, while more objective, also has some basic limitations. For example, it only references the first author, and the author's name can appear in different formats throughout (e.g., middle initials included or missing). For a more extensive critique of the citation index as the basis for ranking individuals and departments, see Cnudde (1986).

Many of these limitations endemic to other approaches for ranking individual academic productivity and scholarly impact would be eliminated by using the number of publications in $A P S R$. It is a more objective measure than reputational surveys. Using only $A P S R$ eliminates the need to weight different types of journals for quality and prestige, although relying solely on $A P S R$ does bias our selection against those individuals and subfields that are oriented towards publishing only books or book chapters. We recognize this bias, but contend that many books are not peer reviewed, nor do they immediately have the wide circulation or prestige attached to them that is enjoyed by an article in APSR.

Despite the difficulties that plague citations as a measure of academic impact, we agree with Klingemann that these are a useful 
and valid method for determining standing in the profession. Our goal, however, is much more narrow in scope than his. We are primarily interested in the profession's leading journal and what frequency of publication in APSR would convey as a portrait of the profession. Of course we are also, as good scientists, curious about the correspondence of the image of the profession conveyed by visibility in $A P S R$ and that conveyed by the number of citations.

One of our basic hypotheses lying behind this empirical endeavor is that there would be a substantial correlation between the frequency of publishing in APSR and the number of citations received in the Social Sciences Citations Index. ${ }^{1}$ Assuming that the profession is essentially a reflection of the intellectual interests of those who do the very best work in the field, then both of these approaches convey the same basic portrait of where the profession has been, where it is currently, and where it may be going in the future. If this is true, then an even more accurate ranking of scholarly impact on the profession would be obtained by combining the number of APSR publications with the number of citationsa measure that we construct and examine below.

\section{Data Collection}

Starting backwards from December 1994, we collected the "Table of Contents" from each issue of APSR published since its initial issue in 1906. Each article found in the Table of Contents formed the unit of analysis (or record) for the initial data set. Included in the data set were regular research articles, research notes, controversies, and major reviews of the literature or some specific substantive field. Book reviews, editorial comments, and communications were excluded from consideration. For each publication included in the data set we coded author names, issue and volume information, starting page, content and the type of article (regular article, research note, etc.).

As we proceeded to construct the data set, we were confronted by a number of data collection dilemmas. The first of these arose because $A P S R$ was a much different journal during the pre-war years than it is today (for a detailed description of the early years of APSR see Patterson, Ripley, and Trish 1988). During its formative years relatively little space in the journal was devoted to substantive articles; thereby little prestige was associated with publishing in APSR during this period. It was not until the mid-1950s that the APSR emphasized superior scholarship. Thus, we decided that it was more appropriate to construct our APSR Hall of Fame, and do our detailed analysis of APSR over the most recent 40 years rather than the 89 years of APSR history. This decision is supported by the conclusions of Patterson, et al. (1988).

Moreover, our empirical analysis of the articles published before the mid-1950s, and only briefly reported here, confirms that comparing today's $A P S R$ to the $A P S R$ published before the mid-1950s would be inappropriate. Focusing our attention on the latest 40 years allows us to provide a more detailed analysis of the scholarly contributions of the two most recent 20-year professional cohorts. Given the historical change in $A P S R$, the APSR Hall of Fame and other descriptions presented below pertain primarily to the latest 40 years of APSR (1954-94). We will, however, from time to time draw some comparisons to the earlier years, thereby highlighting interesting changes that have occurred in the journal.

Other difficulties were also encountered while collecting the information from the APSR Table of Contents. First, the data entry had to be meticulous, especially where the entry of names was concerned. Given that we would ultimately use the name variable to transform the data set into an author-based data set, the names had to be spelled correctly in order to appropriately match the various articles from across the years to a given author. This effort was made more problematic when some authors' initials were used inconsistently. ${ }^{2}$
Another difficulty was the occasional typographical error we discovered in APSR. Yes, even a journal as prestigious as APSR has typos. For example, Heinz Eulau's name was incorrectly spelled "Eutau" in the March 1973 issue, which published his APSA Presidential Address. Similarly, Robert Erikson's APSR publication in 1992 had his name spelled "Erickson," thereafter creating confusion over the correct spelling of his name.

Another APSR convention that gave rise to data collection difficulties involved split-articles and series of articles on a specific topic. For example, three times during the period between 1954-73, APSR split articles into two parts that appeared in different issues. Hanna Pitkin, for instance, was featured in both the December 1965 and the March 1966 issue with parts one and two of an article entitled "Obligation and Consent." This is worth noting because each of these parts count as a separate publication for purposes of tabulating the total number of publications in APSR. A similar situation occurred in the 1954 through 1961 period, when David Fellman published a yearly summary of cases and important events in constitutional law (in the 1960 volume this was split in two parts that appeared in two separate issues). From these articles alone, David Fellman ended up with nine publications in APSR.

The previous information taken from the Table of Contents for each issue of APSR in the last 40 years was also supplemented with data from other sources. To examine the potential relationships between APSR publications and other aspects of each author's career (such as where and when they received their $\mathrm{Ph} . \mathrm{D}$.), we collected biographical information on many of the authors in our data set. Given the large number of authors $(1,612)$ who have published in APSR during the 40 years from 1954 to 1994 , we decided to take a sample of authors rather than attempt to locate biographical information on all authors. We collected biographical information for all of the authors with two or more publications and sampled $28 \%$ of those 
individuals with only one publication. This sample still permitted a detailed analysis of those authors with only one publication, but allowed us to greatly lessen our data collection load.

For biographical information on the authors in our sampled data set, we turned to the APSA Directory of Members. To our surprise, $22 \%$ of the authors in our data set do not appear as members in either the 1994-96 or the 1973 directories. ${ }^{3}$ To fill in the missing data, we next turned to the APSA Guide to Graduate Programs in Political Science. There, too, we fell short of finding information on all of the contributing authors. As a result, we turned to the articles themselves for biographical information where it was possible. Ultimately, there is still a portion of the authors for whom we have not yet gathered complete biographical information. A certain number of these individuals are likely either deceased or members of a profession other than political science. Eventually all of the biographical information on authors from the last 40 years will be collected and presented in a future report.

To examine the correlation between the number of APSR articles published and the number of citations, we collected information on the number of citations for each author who appears in our sampled subset of authors. For authors publishing in APSR from 1974 to the present, we gathered citations from 1971 to 1993 . For authors publishing in APSR between 1954 and 1973, we collected citations from 1956 to 1975.4

The Social Science Citation In$\operatorname{dex}(\mathrm{SSCl})$ is a comprehensive source for tracking the number of citations of publications in political science back to 1956 when the Index first became available. SSCI provides a list of citations for individual authors by article. We followed previous convention for counting lines of citations by measuring the number of centimeters of citations each author received and multiplying that number by 7.05 (Klingemann 1986). For efficiency of data collection we used the $S S C I$ on CD-Rom for the years that it was available (1981 to present).

One problem encountered when using the CD-Rom data, however, was that the CD-Rom and the book versions of SSCI do not count citations in the same manner (Klingemann 1986). For example, no matter how many works by the same author are cited in a given article, the CD-Rom version of the SSCI counts only one citation, whereas the book version of $S S C I$ would report each of the works cited. To correct for this, we generated a random sample of 60 authors for whom we had CD-Rom citation information. Then we measured the lines of citations in the book version of SSCI for the same authors over the same time period. Using these data, we created a constant (2.94) that we used to transform all of the information collected from the CD-Rom into measurements equivalent to the number of citations in the book version of the SSCI.

\section{A Description of the Basic Data}

Even a straightforward description of such basic distributions as the number and types of articles, or the number of authors who have published in APSR over the past 40 years, provides a fascinating and evolving portrait of the profession and its leading journal. From 1906 to 1953 there were 1,776 total articles (including regular articles, research notes, controversies, and major reviews of the literature or some substantive field) published in APSR. Between 1954 and 1994 a total of 1,980 articles were published. Because of changes in the $A P S R$ format, which have allowed more articles to be published in the most recent 20 years, $56 \%$ of the articles in the last 40 years come from the 1974-94 20-year period (thus reflecting what had previously been reported by Patterson, Ripley, and Trish 1988).

These articles varied by type. While $83 \%$ of the articles in the last 40 years have been regular articles, there has been some shift in the types of articles published in APSR during recent years. In the 1954-58 period, $90 \%$ of $A P S R$ content was in the form of regular articles. Beginning with the years 1969-74, controversies gained a prominent position in APSR. Research notes also began to appear more frequently as of the 1984-88 period. For the most recent period (198994), regular articles made up $73 \%$ of $A P S R$ content. Controversies $(10 \%)$ and research notes $(16 \%)$ currently fill the remaining pages in APSR.

The substantive content of these articles has also varied across time. In terms of content, our coding scheme is noticeably different from the one employed by APSR in its annual reports compiled by the journal editor. The APSR uses five broad-based subfield categories: American Politics and Public Policy, Comparative Politics, Normative Political Theory, International Relations, and Formal Theory (Powell 1994). We sought to develop a more substantive portrait of APSR content, and our coding scheme reflects that intention. The category of American Politics and Public Policy, for example, is too broad based for meaningful analysis (it is impossible to determine whether it refers to presidential studies, American electoral behavior, Congress, or some other topic). Working from the APSR Table of Contents, we developed codes that included seven substantive categories (plus one catch-all miscellaneous category). These categories, listed in Table 1, are more substantively focused, rather than determined by subfield or the country involved in the reported research.

As Table 1 demonstrates, the $A P S R$ over the last 40 years has not been dominated by any particular substantive topic; no one area comprises more than $20 \%$ of the total content. Nevertheless, some substantive areas receive more attention than others. Theoretical and philosophical articles have comprised the highest percentage of APSR content (18\%). The other seven substantive areas each make up between 8-14\% of APSR content.

Since looking at APSR content overall provides little insight into 


\begin{tabular}{|c|c|c|c|c|}
\hline Content & $1906-53$ & $1954-73$ & $1974-94$ & $\begin{array}{c}\text { Total } \\
\text { (1954-94) } \\
\end{array}$ \\
\hline Political Behavior & $6.7 \%$ & $9.0 \%$ & $15.5 \%$ & $12.6 \%$ \\
\hline Parties/Interest Groups & 12.9 & 19.8 & 10.9 & 14.8 \\
\hline Foreign/Comparative & 14.5 & 19.5 & 6.9 & 12.5 \\
\hline International Relations & 8.3 & 6.4 & 9.9 & 8.4 \\
\hline Institutions & 35.6 & 13.8 & 8.6 & 10.9 \\
\hline Theory & 11.1 & 21.5 & 15.1 & 17.9 \\
\hline Study/Methods & 0.8 & 7.5 & 17.0 & 12.8 \\
\hline Misc. & 10.1 & 2.5 & 15.9 & 10.1 \\
\hline$n=$ number of articles & 1779 & 870 & 1110 & 1980 \\
\hline \multicolumn{5}{|c|}{ Source: The University of Iowa APSR Article Data Set } \\
\hline \multicolumn{5}{|c|}{ Category Descriptions } \\
\hline \multicolumn{5}{|c|}{ Political Behavior: Voting and Elections, Public Opinion } \\
\hline \multicolumn{5}{|c|}{ Parties/Interest Groups: Political Parties and Interest Groups } \\
\hline \multicolumn{5}{|c|}{ Foreign/Comparative: Foreign Policy or Comparative Focus } \\
\hline \multicolumn{5}{|c|}{ International Relations: International Relations or Military/Defense } \\
\hline \multicolumn{5}{|c|}{ Institutions: Legislative, Presidency, Judiciary, Bureaucracy } \\
\hline \multicolumn{5}{|c|}{ Theory: Formal or Normative } \\
\hline \multicolumn{5}{|c|}{ Study/Methods: A particular descriptive study or methodology } \\
\hline Misc.: Includes Wom & & & & \\
\hline
\end{tabular}

either the history or the future of the discipline, we next turn to an examination of content across time. The variation in content across time should provide clues to both where the discipline has been substantively and where it might be going.

The number of articles in two substantive areas in particular has declined significantly during the past 40 years. The study of political parties and interest groups and foreign/comparative politics both comprised roughly $20 \%$ of $A P S R$ content between 1954 and 1973. In the most recent 20 years, however, both have declined to $11 \%$ and $7 \%$ respectively. Conversely, political behavior and articles focused on a particular type of study or methodology have increased as a proportion of the overall content. Both made up less than $10 \%$ of journal content in the earlier period and have now grown to $16 \%$ and $17 \%$ respectively.

However, looking at these changes in journal content in more detail (see Figure 1) indicates that there has been even more variation across time. Political behavior had its most significant gains from 1959 to 1978 , where it rose steadily from $6 \%$ to a high point of $17 \%$. Since that time, it has leveled off a bit to $15 \%$ in the most recent period of 1989-94. Study/methods saw its biggest gains from 1969-83, going from $9 \%$ to $24 \%$. It has also declined since its high point of $24 \%$ to $15 \%$ and appears to be leveling. Foreign and Comparative Politics saw steady decline in levels of APSR content from 1954-83 (from $25 \%$ to $5 \%$ ) and has since rebounded slightly to $8 \%$. The study of political parties and interest groups, on the other hand, saw most of its loss in a single 10-year period, from 1969 to 1978 where it went from $24 \%$ to $10 \%$ of $A P S R$ content. With some variation, it has maintained that level through the most recent period.

No doubt this variation in content is the result of numerous factors including the shifting focus of the discipline, the responsiveness of reviewers, the emergence of new data, and changes in editorial decision making. Our data do not include measures that would allow us to address the potential impact of any of these factors on the apparent changes. Nevertheless, the data do demonstrate that while the preponderance of major subfields like American Politics and Public Policy may appear relatively stable over time (Patterson, Ripley, and Trish 1988; Powell 1994), breaking these areas into finer-grained substantive categories reveals significant within-field fluctuation.

In addition to content variation over time, we also find change in the number of authors publishing in APSR during different historical periods. Over the last 40 years, 1,612 authors have published 1,980 articles (articles, research notes, controversies, and major subfield review essays) in APSR, whereas only $\mathbf{8 8 0}$ authors published almost the same number of articles $(1,776)$ between 1906 and 1953. The number of authors publishing in APSR has increased significantly during the most recent 20-year period relative to the earlier 20-year period. Between 1954 and 1973 there were 700 authors, and between 1974 and 1994 there were 1,052 authors publishing in APSR. One hundred and forty authors published in both 20 year periods.

The increased number of authors over time is not surprising given that more articles have appeared in the journal during the more recent 20 years. Nevertheless, this does not fully account for the increased number of authors. A dramatic increase in the percentage of multiauthored articles in APSR occurred over the most recent 20 years. Over the 40 years, $70 \%$ of the articles have one author. But that percent has not been constant over time. For example, single-authored articles made up nearly $92 \%$ of the articles published between 1954 and 1958. In contrast, single-author publications accounted for only $49 \%$ of those articles published between 1989 and 1994. To further emphasize this change that has occurred over time, single-author publications comprised over $96 \%$ of all articles between 1906 and 1953. This explosion in the number of multiauthor articles has most certainly contributed to the increase in the number of authors who published in the APSR during the recent 20 years.

An overwhelming majority of the authors have been male, but less so in the most recent 20 years. Between 1954 and 1973 just over $2 \%$ of the authors were female, and for the most recent 20 years (1974-94) $11 \%$ were female. While this represents a significant increase in the percentage of articles contributed by women, it is still far below the percentage of women in the profes- 


\section{FIGURE 1}

Change in APSR Content, 1954-1994

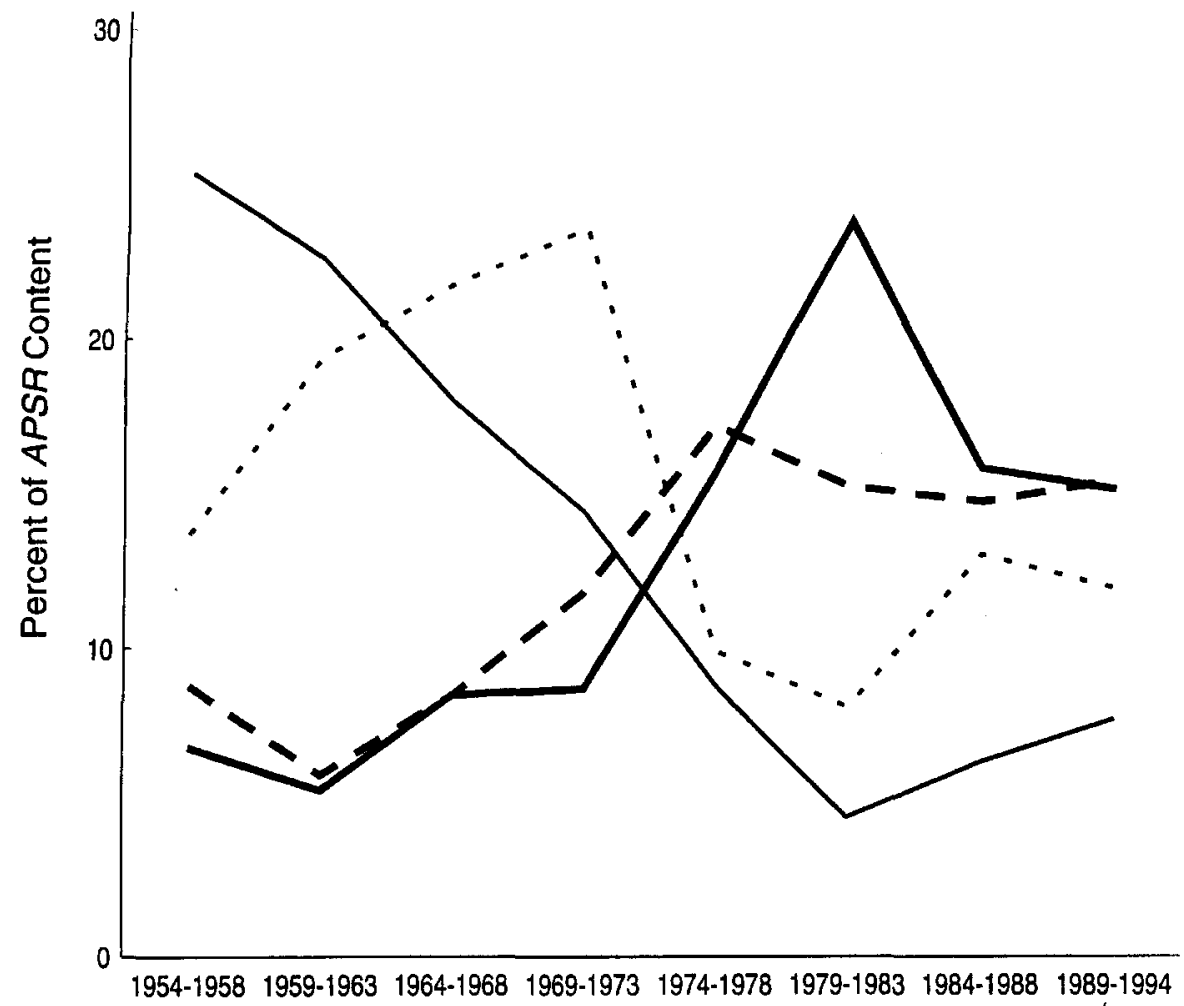

Year

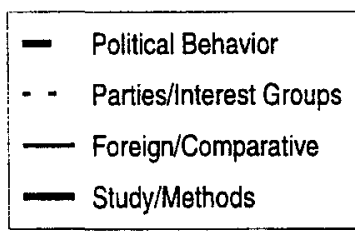

Source: The University of Iowa APSR Article data set

sion. One might wonder, in this gender-sensitive world, and when examining a male-dominated discipline, whether the female authors were more likely to be secondary rather than primary authors of publications in APSR. The empirical evidence demonstrates virtually no relationship between gender and order of authorship. Women were not any more, nor any less likely to be, secondary rather than primary authors.

\section{Frequency of Publication in the APSR}

When constructing our APSR Hall of Fame, we noticed that only $34 \%$ (544) of the 1,612 authors have published in APSR more than once. Table 2 provides a breakdown of the number of authors publishing in APSR by frequency of publication since 1954 . Why have only a third of the authors publishing in our discipline's top journal managed to publish in APSR more than once?

One possible reason is that many of these single-time publishers are secondary authors (meaning they coauthored the article but they were not the first author listed). Secondary authors (when not listed alphabetically) tend to contribute less and may be less successful than single or primary authors in publishing in APSR again. However, between 1954 and 1974, only $18 \%$ of the single-time publishers were secondary authors.
On the other hand, during the most recent 20 years the percentage of single-time publishers, who are secondary authors, increased substantially. During the 1974 to 1994 period, $37 \%$ of one-time publishers in APSR were secondary authors. Thus, the percentage of one-time publishers who are secondary authors has doubled from one 20-year period to the next. Yet, the fact that less than $30 \%$ of the one-time $A P S R$ publishers over the entire 40-year period are secondary authors, tends to refute the argument that few political scientists publish in APSR more than once because many of the one-time publishers are secondary authors.

A more simple and plausible reason why very few authors publish more than once in APSR is that the journal has very stringent publication standards. Recent rejection rates are around 90\% (Powell 1994; Patterson, Ripley, and Trish 1988), and publication was not that much easier in 1947 when editor Frederic A. Ogg said that "not more than one article in four" was being accepted (Patterson, Ripley, and Trish 1988, 919).

Has it become more difficult to get published in APSR over the last 40 years? If it used to be easier to get published in APSR than it is today, we would expect that a larger percentage of authors should have published more than once in previous eras when the profession was smaller in size, and when there was no peer review process. According to Patterson, et al. (1988), the APSR peer review process was implemented by Austin Ranney,

\section{TABLE 2}

Number of Authors by Number of Publications, 1954-94

\begin{tabular}{ccr}
\hline $\begin{array}{c}\text { Number of } \\
\text { Publications }\end{array}$ & $\begin{array}{c}\text { Number of } \\
\text { Authors }\end{array}$ & Percent \\
\hline 1 & 1060 & 65.8 \\
2 & 288 & 17.9 \\
3 & 127 & 7.9 \\
4 & 65 & 4.0 \\
5 & 27 & 1.7 \\
$6-9$ & 33 & 2.0 \\
$\geq 10$ & 12 & 0.7 \\
Total & 1612 & 100.00 \\
\hline Source: The University of Iowa APSR \\
Author Data Set & &
\end{tabular}


who was editor from 1966-69. But a comparison between the two most recent 20-year periods, looking at how many authors publish more than once, suggests that the difficulty of publishing in APSR has remained relatively constant. Between 1954 and 1973 only $28 \%$ of the authors published more than once, and in the most recent 20 years only $32 \%$ of the authors have published more than once. Editors before implementation of the peer review process (but during the most recent 40 years) apparently were just as selective as editors and their reviewers have been since peer review was implemented in 1967. We suggest that the reason only a third of the authors who publish in APSR do it again is simply because $A P S R$ has limited space, and it has always been difficult to earn some of that space.

\section{The Hall of Fame}

Of the authors who have published more than once in the $A P S R$ during the past 40 years, an elite group of 45 authors have published more than five times. From these 45, we inducted into the APSR Hall of Fame only those 12 authors who have published most frequently by using a cutoff of 10 or more articles (see Table 3). ${ }^{5}$ This APSR Hall of Fame contains less than $1 \%$ of all the political scientists published in the APSR over the last 40 years. All of the inductees received their degrees before 1972 and, with the exception of William Riker and Edward N. Muller, are still active and have published in APSR since 1986. Only two of the authors (Muller and Ordeshook) had their first publication in APSR before receiving their degrees, but all of the authors got their second publication within three years of their first publication. All but one of the authors (Niemi, who seems most consistent) have had multi-publication years, and three (Erikson, A. Miller, and Shepsle) had one year in which they published three times in the APSR. ${ }^{6}$

Younger scholars may claim they are disadvantaged by having fewer years to meet the 10 publications

TABLE 3

APSR Hall of Fame, 1954-94

\begin{tabular}{|c|c|c|c|c|c|}
\hline Name & Cohort $^{d}$ & $\begin{array}{l}\text { First } \\
\text { Author }\end{array}$ & $\begin{array}{c}\text { Total } \\
\text { Articles }\end{array}$ & $\begin{array}{c}\text { Combined } \\
\text { Total }\end{array}$ & $\begin{array}{c}\text { Lines of } \\
\text { Citations }^{e} \\
\end{array}$ \\
\hline $\begin{array}{l}\text { Riker, William H.* (deceased) } \\
\text { University of Rochester }\end{array}$ & 1 & 9.00 & 9.00 & 16.00 & 3760 \\
\hline $\begin{array}{l}\text { Ph.D., Harvard-1948b } \\
\text { Political Philosophyc }\end{array}$ & 2 & 4.00 & 7.00 & & \\
\hline $\begin{array}{l}\text { Muller, Edward } N \text {. (deceased) } \\
\text { University of Arizona }\end{array}$ & 1 & 3.00 & 4.00 & 14.00 & 968 \\
\hline $\begin{array}{l}\text { Ph.D., University of Iowa-1971 } \\
\text { Comparative Politics }\end{array}$ & 2 & 7.00 & 10.00 & & \\
\hline $\begin{array}{l}\text { Ordeshook, Peter C. } \\
\text { California Institute of Technology }\end{array}$ & 1 & 2.00 & 5.00 & 14.00 & 515 \\
\hline $\begin{array}{l}\text { Ph.D., University of Rochester-1969 } \\
\text { Political Philosophy and Theory }\end{array}$ & 2 & 2.00 & 9.00 & & \\
\hline $\begin{array}{l}\text { Abramson, Paul } \boldsymbol{R} \text {. } \\
\text { Michigan State University }\end{array}$ & 1 & 1.00 & 1.00 & 11.0 & 1980 \\
\hline $\begin{array}{l}\text { Ph.D., University of California } \\
\text { (Berkeley)-1967 } \\
\text { Comparative Politics }\end{array}$ & 2 & 7.00 & 10.00 & & \\
\hline $\begin{array}{l}\text { Brams, Steven J. } \\
\text { New York University }\end{array}$ & 1 & 4.00 & 5.00 & 11.00 & 1954 \\
\hline $\begin{array}{l}\text { Ph.D., Northwestern University-1966 } \\
\text { Political Philosophy and Theory }\end{array}$ & 2 & 6.00 & 6.00 & & \\
\hline $\begin{array}{l}\text { Jennings, } \boldsymbol{M} \text {. Kent } \\
\quad \text { University of California (Santa Barbara) }\end{array}$ & 1 & 3.00 & 4.00 & 11.00 & 1995 \\
\hline $\begin{array}{l}\text { Ph.D., University of North Carolina- } \\
1961\end{array}$ & 2 & 5.00 & 7.00 & & \\
\hline $\begin{array}{l}\text { Women and Politics } \\
\text { Miller, Warren E.* } \\
\text { Arizona State }\end{array}$ & 1 & 2.00 & 6.00 & 11.00 & 2108 \\
\hline $\begin{array}{l}\text { Ph.D., Syracuse-1954 } \\
\text { American Government and Politics }\end{array}$ & 2 & 2.00 & 5.00 & & \\
\hline $\begin{array}{l}\text { Niemi, Richard } G \text {. } \\
\text { University of Rochester }\end{array}$ & 1 & 1.00 & 3.00 & 11.00 & 638 \\
\hline $\begin{array}{l}\text { Ph.D., University of Michigan-1971 } \\
\text { American Government and Politics }\end{array}$ & 2 & 5.00 & 8.00 & & \\
\hline $\begin{array}{l}\text { Erikson, Robert } S \text {. } \\
\quad \text { University of Houston }\end{array}$ & 1 & 2.00 & 2.00 & 10.00 & 1042 \\
\hline $\begin{array}{l}\text { Ph.D., University of Illinois-1971 } \\
\text { Methodology }\end{array}$ & 2 & 5.00 & 8.00 & & \\
\hline $\begin{array}{l}\text { Miller, Arthur } \mathrm{H} . \\
\text { University of Iowa }\end{array}$ & 1 & - & - & 10.00 & 2100 \\
\hline $\begin{array}{l}\text { Ph.D., University of Michigan-1971 } \\
\text { Comparative Politics }\end{array}$ & 2 & 9.00 & 10.00 & & \\
\hline $\begin{array}{l}\text { Shepsle, Kenneth A. } \\
\text { Harvard } \\
\text { Ph.D., University of Rochester-1970 } \\
\text { American Government and Politics }\end{array}$ & 1 & 4.00 & 1.00 & 10.00 & 1757 \\
\hline $\begin{array}{l}\text { Wolfinger, Raymond } \boldsymbol{E} \text {. } \\
\text { University of California (Berkeley) } \\
\text { Ph.D., Yale-1961 } \\
\text { American Government and Politics }\end{array}$ & 2 & 7.00 & 7.00 & 10.00 & 1526 \\
\hline \multicolumn{6}{|c|}{$\begin{array}{l}\text { Source: The University of Iowa APSR Author Data Set } \\
\text { a affiliation as listed in the APSA Directory of Members. } \\
\text { b where and when Ph.D. was received as listed in the APSA Directory of Members. } \\
\text { c first field as listed in the APSA Directory of Members. } \\
\text { d Cohort }=1 \text { for } 1954-1973,=2 \text { for } 1974-1994 \text {. } \\
\text { e citations collected from } 1956 \text { to } 1993 \text {. } \\
\text { * Author had publications well before the peer review process was officially implemented } \\
\text { in } 1967 \text {. }\end{array}$} \\
\hline
\end{tabular}

requirement, so we compared the top publishers of the most recent 20 years to the previous generation of political scientists. Table 4 lists the top publishers in the APSR for each 20-year cohort. Both lists are similar to the 40-year Hall of Fame list-seven of the top nine since 1974 and three of the top seven between 1954 and 1973 are also in the Hall of Fame. Another 20 years will certainly lead to more induc- 
TABLE 4

Most Published in APSR, 20-Year Cohorts

\begin{tabular}{cc}
\hline Name & $\begin{array}{c}\text { Number of } \\
\text { APSR } \\
\text { Publications }\end{array}$ \\
\hline 1954-1973* \\
\hline
\end{tabular}

Fellman, David

Riker, William H.

Wolfinger, Raymond E.

Dahl, Robert A.

Miller, Warren E.

Stokes, Donald E.

Brams, Steven J.

Deutsch, Karl W.

Eulau, Heinz

McClosky, Herbert

Oppenheim, Felix E.

Ordeshook, Peter C.

Schubert, Glendon A.

Walker, Jack L.

Wolin, S.S.

9

9.

7

6

6

5

5

5

5

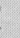

5

1974-1994

Abramson, Paul R.

Miller, Arthur H.

Muller, Edward N.

Ordeshook, Peter C.

Shepsle, Kenneth A.

Bueno de Mesquita, Bruce

Erikson, Robert S.

Ferejohn, John A.

Niemi, Richard

Ostrom, Charles W.

Source: The University of Iowa APSR

Author Data Set

* With the exception of Brams, Ordeshook, Walker, and Wolfinger, all authors had publications well before the peer review process was officially implemented in 1967.

tions into the APSR Hall of Fame; however, given the difficulty in publishing in $A P S R$ and given that many of today's younger leading contributors are still active, it is likely that today's leaders will also be among tomorrow's contributors.

Members of the most recent 20year cohort may also argue that publications before the peer review process was formally implemented in 1967 should be weighted less given that it may have been easier to publish articles in APSR without the scrutiny of one's colleagues. Excluding publications before 1967, however, changes the APSR Hall of Fame very little. Given that some articles were peer reviewed before 1967 (Patterson, Ripley, and Trish 1988, 20), only Riker and W. E. Miller are significantly influ- enced if publications well before 1967 are discounted. ${ }^{7}$

\section{Citations-An Alternative Perspective}

For many years, academic performance has been measured by counting the number of citations received from peers in the profession (Klingemann 1986; Klingemann, Grofman, and Campagna 1989). However, the number of citations and the number of publications in APSR do not necessarily capture the same aspects of professional achievement. The frequency of citations reflects scholarly acceptance or the acknowledgment of intellectual importance through using others' research. A significant number of citations over a period of time reflects an established track record or staying power for an idea or research that has made an enduring contribution to the discipline. A journal acceptance, on the other hand, is more likely to give emphasis to the novelty of the ideas presented in a paper, and these might eventually, but not necessarily, find acceptance among others in the discipline. However, if $A P S R$ is attracting the best scholars in the field and is publishing the most telling rather than simply the most current or popular research, then we should find a significant correlation between the frequency of publishing in APSR and the frequency of citations.

The empirical results demonstrate a positive correlation between publishing in APSR and the number of citations, but this correlation is only a moderate one, $r=$ .37. This relatively low correlation suggests that publication in APSR does not necessarily lead to a large impact on the discipline. ${ }^{8}$ The discrepancy in the rankings produced by these two different approaches can be seen in Table 5 which lists the 50 most frequently cited authors who have published in APSR during the 1974-94 periods regardless of the number of APSR publications. R. Brown comes out on top in Table 5 and Norman H. Nie, largely due to his often cited SPSS manual, comes in second. Only one
TABLE 5

Citations Leaders Among Authors Published in the APSR, 1974-94

\begin{tabular}{|c|c|c|}
\hline Name & $\begin{array}{c}\text { APSR } \\
\text { Publications } \mathrm{s}^{\mathrm{a}}\end{array}$ & Citations $^{b}$ \\
\hline Brown, $\mathbf{R}$. & 2 & 14423 \\
\hline Nie, N.H. & 1 & 14269 \\
\hline Dixon, W.J. & 2 & 9693 \\
\hline Olson, M. & 1 & 8903 \\
\hline March, J.G. & 1 & 8487 \\
\hline Jones, E. & 1 & 6542 \\
\hline Huntington, S.P. & 1 & 5884 \\
\hline Wildavsky, A. & 3 & 5568 \\
\hline Tullock, G. & 2 & 5505 \\
\hline Lindblom, C.E. & 2 & 5450 \\
\hline Rapoport, A. & 2 & 5232 \\
\hline Axelrod, R. & 3 & 5211 \\
\hline Fishburn, P.C. & 4 & 5108 \\
\hline Converse, P.E. & 5 & 4351 \\
\hline Smith, J.A. & 1 & 4350 \\
\hline Brown, C. & 4 & 4121 \\
\hline Greenberg, J. & 2 & 4040 \\
\hline Dahl, R. & 1 & 3919 \\
\hline Dawes, R.M. & 5 & 3561 \\
\hline Riker, W.H. & 7 & 3503 \\
\hline Verba, S. & 2 & 3467 \\
\hline Cooper, J. & 2 & 3403 \\
\hline Johnson, J. & 2 & 3275 \\
\hline Mitchell, J. & 1 & 3168 \\
\hline Piven, F.F. & 1 & 3145 \\
\hline Lowi, T.J. & 2 & 2998 \\
\hline Lijphart, A. & 2 & 2957 \\
\hline Fiorina, M.P. & 7 & 2936 \\
\hline Przeworski, A. & 3 & 2866 \\
\hline Smith, V.K. & 1 & 2832 \\
\hline Fischer, C.S. & 1 & 2564 \\
\hline Inglehart, R. & 5 & 2536 \\
\hline Sears, D.O. & 2 & 2366 \\
\hline Miller, A.H. & 10 & 2100 \\
\hline Baron, D.P. & 4 & 2088 \\
\hline Cohen, M.D. & 2 & 2066 \\
\hline Thompson, W.R. & 3 & 2016 \\
\hline Burnham, W.D. & 2 & 1994 \\
\hline Carmines, E.G. & 4 & 1988 \\
\hline Smith, R.A. & 1 & 1986 \\
\hline Fenno, Jr. R.F. & 2 & 1985 \\
\hline Abramson, P.R. & 10 & 1980 \\
\hline Good, I.J. & 1 & 1977 \\
\hline Sigelman, L. & 1 & 1949 \\
\hline Mckelvey, R.D. & 4 & 1868 \\
\hline Taylor, S. & 2 & 1856 \\
\hline Brams, S.J. & 6 & 1800 \\
\hline Myerson, R.B. & 2 & 1797 \\
\hline Miller, W.E. & 5 & 1794 \\
\hline Eckstein, H. & 2 & 1754 \\
\hline \multicolumn{3}{|c|}{$\begin{array}{l}\text { Source: The University of Iowa APSR } \\
\text { Author Data Set. } \\
\text { a publications in the APSR from } 1974 \text { to } \\
1994 \text {. } \\
\text { b citations collected from } 1971 \text { to } 1993 \text {. }\end{array}$} \\
\hline
\end{tabular}

Hall of Fame member (Riker) is in the 1974-94 top 25 citation leaders, although four others do appear among the 50 most frequently cited authors (in order of rank these are A. Miller, Abramson, Brams, and W. Miller).

In part, the moderately sized cor- 
TABLE 6

Professional Visibility Index* (1954-94)

\begin{tabular}{|c|c|c|c|}
\hline Name & Publications & Citations & PVI \\
\hline Riker, W.H. & 16 & 3759 & 60.15 \\
\hline Dahl, R.A. & 7 & 6107 & 42.75 \\
\hline Converse, P.E. & 8 & 4196 & 33.57 \\
\hline Wildavsky, A. & 5 & 6633 & 33.16 \\
\hline Axelrod, $\mathbf{R}$. & 5 & 5254 & 26.27 \\
\hline Jennings, M.K. & 11 & 2149 & 23.64 \\
\hline Miller, W.E. & 11 & 2108 & 23.19 \\
\hline Brams, S.J. & 11 & 1952 & 21.47 \\
\hline Miller, A.H. & 10 & 2100 & 21.00 \\
\hline Russett, B.M. & 8 & 2623 & 20.99 \\
\hline Abramson, P.R. & 11 & 1885 & 20.73 \\
\hline Fiorina, M.P. & 7 & 2936 & 20.55 \\
\hline Inglehart, $\mathrm{R}$. & 7 & 2639 & 18.47 \\
\hline Dawes, R.M. & 5 & 3561 & 17.81 \\
\hline Shepsle, K.A. & 10 & 1684 & 16.84 \\
\hline Lowi, T.J. & 5 & 3086 & 15.43 \\
\hline Przeworski, A. & 5 & 2786 & 13.93 \\
\hline Wolfinger, R.E. & 10 & 1355 & 13.55 \\
\hline Muller, E.N. & 14 & 966 & 13.53 \\
\hline Epstein, L.D. & 7 & 1814 & 12.70 \\
\hline Deutsch, K.W. & 5 & 2372 & 11.86 \\
\hline Lane, R.E. & 6 & 1972 & 11.83 \\
\hline Walker, J.L. & 6 & 1963 & 11.78 \\
\hline Aldrich, J.H. & 7 & 1680 & 11.76 \\
\hline Ferejohn, J.A. & 9 & 1256 & 11.31 \\
\hline Sullivan, J.L. & 6 & 1748 & 10.49 \\
\hline Grofman, B.N. & 8 & 1124 & 8.99 \\
\hline Powell, R. & 7 & 1271 & 8.89 \\
\hline Ostrom, C.W. Jr. & 8 & 1028 & 8.23 \\
\hline Page, B.I. & 6 & 1350 & 8.10 \\
\hline Hibbs, Jr. D.A. & 5 & 1607 & 8.03 \\
\hline Ordeshook, P.C. & 14 & 517 & 7.24 \\
\hline Gibson, J.L. & 6 & 1091 & 6.54 \\
\hline Moe, T.M. & 6 & 1062 & 6.37 \\
\hline Rothman, S. & 5 & 1032 & 5.16 \\
\hline Markus, G.B. & 5 & 935 & 4.67 \\
\hline
\end{tabular}

TABLE 6 continued

Professional Visibility Index* (1954-94)

\begin{tabular}{|c|c|c|c|}
\hline Name & Publications & Citations & PVI \\
\hline Merelman, R.M. & 6 & 777 & 4.66 \\
\hline Wright, Jr. G.C. & 5 & 850 & 4.25 \\
\hline Stimson, J.A. & 6 & 686 & 4.11 \\
\hline Greenstein, F.I. & 5 & 787 & 3.93 \\
\hline Beck, P.A. & 5 & 726 & 3.63 \\
\hline Midlarsky, M.I. & 5 & 717 & 3.58 \\
\hline Jackson, J.E. & 5 & 711 & 3.56 \\
\hline Eulau, $\mathrm{H}$. & 5 & 709 & 3.55 \\
\hline Caldeira, G.A. & 7 & 505 & 3.54 \\
\hline Rae, D.W. & 5 & 700 & 3.50 \\
\hline Orbell, J.M. & 8 & 436 & 3.48 \\
\hline Niemi, R.G. & 11 & 301 & 3.32 \\
\hline Mcclosky, H. & 5 & 656 & 3.28 \\
\hline Searing, D.D. & 8 & 364 & 2.91 \\
\hline Rosenthal, H. & 8 & 358 & 2.87 \\
\hline Austen-Smith, D. & 6 & 450 & 2.70 \\
\hline Stokes, D.E. & 6 & 405 & 2.43 \\
\hline Lodge, M. & 5 & 473 & 2.37 \\
\hline Norpoth, H. & 5 & 453 & 2.27 \\
\hline Mackuen, M.B. & 7 & 297 & 2.08 \\
\hline Bendor, J. & 6 & 323 & 1.94 \\
\hline Silver, B.D. & 6 & 323 & 1.94 \\
\hline Feld, S.L. & 5 & 313 & 1.57 \\
\hline Hinich, M.J. & 5 & 310 & 1.55 \\
\hline Keech, W.R. & 5 & 290 & 1.45 \\
\hline Erikson, R.S. & 10 & 138 & 1.38 \\
\hline Fellman, D. & 9 & 128 & 1.15 \\
\hline Gunnell, J.G. & 6 & 184 & 1.10 \\
\hline Wallerstein, $\mathbf{M}$. & 5 & 173 & 0.87 \\
\hline Wolin, S.S. & 5 & 155 & 0.78 \\
\hline Schubert, Jr. G.A. & 6 & 105 & 0.63 \\
\hline Oppenheim, F.E. & 5 & 104 & 0.52 \\
\hline Oppenheimer, J.A. & 6 & 82 & 0.49 \\
\hline Bueno de Mesquita, B. & 8 & 61 & 0.49 \\
\hline Black, G.S. & 5 & 84 & 0.42 \\
\hline Rusk, J.G. & 5 & 65 & 0.32 \\
\hline
\end{tabular}

Source: The University of Iowa APSR Author Data Set.

* The Professional Visibility Index is calculated by multiplying publications by citations and then dividing by 1,000. relation between the number of citations and the frequency of publishing in APSR is a reflection of problems endemic to the $S S C I$ that introduce measurement noise into the comparison. The $S S C I$ lists authors by last name, and then first initial or first and middle initial. This created problems when counting the citations of authors with common last names. For example, there are many R. Browns publishing in the social sciences, and it was difficult to pick out only political science entries for so many authors with common last names.

Since there were a number of common last names (for example Brown, Jones, Miller, and Smith) in the top citations list, we went back to the $S S C I$ to check the accuracy of our initial data collection.

We confirmed our belief that au- thors with common last names tended to be inaccurately counted. They would either receive credit for many citations that were not related to political science, or their work would get listed under multiple headings (for example, Ronald E. Brown's work may be undercounted because it may be listed under R. Brown and R.E. Brown). Given these types of problems with the $S S C I$, we suggest that a more valid and accurate measure of visibility in the profession could be constructed by combining the number of citations and the frequency of publishing in APSR.

Citations and publication in the discipline's top journal are both measures of professional visibility and performance. Political scientists who keep up with the current literature consistently refer to APSR. On the other hand, high quality work tends to get noticed and cited frequently regardless of where it is published. Thus, we constructed a Professional Visibility Index (PVI) by multiplying the total number of APSR publications by the total citations received over the last 40 years and dividing by 1,000 . In theory, we can calculate the PVI for all the authors in our data set.

Table 6 presents the PVI scores for the 72 scholars who have published five or more articles in the APSR during the past 40 years (roughly the top $4 \%$ in Table 2). Many of the individuals from the Hall of Fame (Table 3) continue to rank highly in the PVI list. For example, William Riker is still the 
leader, and six of the top twelve on the PVI ranking are members of the APSR Hall of Fame. Moreover, all but two of the Hall of Fame members end up in the top 25 as determined by the PVI ranking. In place of surveys that rely on reputational rankings, we offer the PVI as a valid and reasonably accurate measure of visibility and performance, as it considers both publishing in the discipline's top peer review journal and the number of citations from one's peers.

\section{Conclusion}

The analysis of who has published in the APSR during the past 40 years, particularly when combined with frequency of citations, provides yet another way to assess standing in the profession. It combines the accomplishment feature (perhaps the equivalent of Babe Ruth getting so many home-runs off so many different pitchers over a career) with the recognition feature so important to accumulative scholarship. We believe that multipleitem indicators can only make for sounder assessments. In a future report we will return to apply this combined measure to an assessment of graduate programs.

The analysis of publications in $A P S R$ also reveals an evolving portrait of the discipline's leading journal, as well as the discipline itself. The composition and content of the APSR has clearly changed over the years. Some of those changes have been reported previously by $A P S R$ editors, such as the increase in the number of articles published per issue. However, our analysis reveals that other types of changes, which have not been noted by the editors, have also occurred. For example, when a more substantive coding of the APSR content is employed, significant changes in APSR content are observed across time.

Most of the changing features of who publishes in APSR, however, appear to be a reflection of shifts taking place in the discipline rather than changes in APSR per se. For example, the increased number of women publishing in APSR in re- cent years has to be a reflection of the increasing proportion of women in the discipline. As the proportion of women in political science continues to rise, we should expect that the number of female authors in $A P S R$ will also continue to rise.

Perhaps an even more interesting change occurring in the profession is implied by the sharp rise in multiple-authored articles during the most recent 20-year period (84\% and $59 \%$ of $A P S R$ articles in the 1954-74 and 1974-94 periods, respectively, were single-authored). This rise in multiple-authored articles indicates that a greater degree of collaboration is occurring in the discipline now than was the case 20 years ago. Empirical evidence reflecting the rate of multiple-authored articles in a number of different journals, in addition to $A P S R$, during the past 40 years (see Table 7) strongly suggests that increasing collaboration is a trend occurring in the social sciences more generally, although some areas of political science are experiencing this trend more than other areas. In the six social science journals we examined, all showed an increase in collaborative articles over the last 20 years. The most dramatic changes occurred in the substantively broad-based political science journals (American Journal of Political Science, American Political Science Review, and Journal of Politics).

No doubt there are a number of explanations for this trend toward increasing collaboration. We would like to think it reflects increased mentoring in the discipline, but our data do not support this interpretation. For example, if mentoring was the explanation, we should find that primary authors (whom we assume to be the mentors) received their Ph.D.s much earlier than the secondary authors (those whom we assume are being mentored). Moreover, we would expect that those who published for the first time in APSR prior to getting their Ph.D. (roughly $8 \%$ of all first-time publishers in the APSR) would be predominantly secondary authors. The empirical evidence, however, does not support either of these hypotheses. The increased collaboration does not appear to be the result of increased mentoring.

Other plausible explanations that have come to mind must remain more speculative as they are not readily tested with the data at hand. We suggest, however, that this rise in collaboration may be the result of technical advances in computing and electronic mail capabilities, making it easier for members of the discipline to collaborate. Moreover, the increasing availability of complex data sets, as well as the ever increasing complexity and sophistication of analysis methods, has made collaboration a necessity. Regardless of the explanations for this trend, it would seem that a by-product of the change ought to be higher quality scholarship, and a more close-knit, harmonious discipline.

While we will have to wait for the future to determine if harmony in the discipline increases, some other trends associated with the rise in collaboration appear more imminent. For example, the data already reveal an emerging shift in the amount of time that occurs between obtaining the Ph.D. and get-
TABLE 7

Percent of Articles with Multiple Authors by Cohort

\begin{tabular}{lcc}
\hline \multicolumn{1}{c}{ Journal } & $1954-73$ & $1974-94$ \\
\hline American Political Science Review & 16 & 41 \\
American Sociological Review & 31 & 44 \\
American Journal of Political Science & 20 & 40 \\
World Politics & 4 & 14 \\
Journal of Politics & 10 & 57 \\
Comparative Political Studies & 25 & 28 \\
\hline
\end{tabular}

Note: The data examined in this table come from the APSR Article Data Set as well as from the Table of Contents of the other journals. For journals other than the APSR, we collected information on every other volume from 1954-94. 


\begin{tabular}{|c|c|c|c|c|}
\hline \multirow[b]{2}{*}{ Years } & \multicolumn{2}{|c|}{$1954-73$} & \multicolumn{2}{|c|}{$1974-94$} \\
\hline & Frequency & Percent & Frequency & Percent \\
\hline 0 or less & 35 & 15.6 & 30 & 10.6 \\
\hline 1 & 29 & 12.9 & 16 & 5.7 \\
\hline 2 & 33 & 14.7 & 24 & 8.5 \\
\hline 3 & 25 & 11.1 & 23 & 8.1 \\
\hline 4 & 18 & 8.0 & 27 & 9.5 \\
\hline 5 & 14 & 6.2 & 26 & 9.2 \\
\hline 6 & 19 & 8.4 & 20 & 7.1 \\
\hline $7-9$ & 16 & 7.1 & 42 & 14.8 \\
\hline $10-19$ & 25 & 11.1 & 60 & 21.2 \\
\hline$\geq 20$ & 11 & 4.9 & 15 & 5.3 \\
\hline Total & 225 & $100 \%$ & 283 & $100 \%$ \\
\hline
\end{tabular}

ting the first publication in APSR. Over the 40-year period, roughly two-thirds of all first-time $A P S R$ publications occurred within six years of getting the Ph.D. (see Table 8), and on the average nearly five years passed before getting a second APSR publication. The impression this conveys is that most $A P S R$ authors were crafting an article from their dissertation research, possibly with the hope that it would help in getting tenure, and then moving on to publish later work in journals with higher acceptance rates or in books.

That impression is now changing as collaboration increases. First, the sole-authored article has become rarer. Secondly, it is taking longer from date of Ph.D. to first publication in APSR (the mean was five years for the earlier 20 years; and seven years for the most recent period). Finally, less time is elapsing between the first and second publication in the $A P S R$ (during the earlier 20-year period the average time elapsed was nearly six years; in the most recent 20-year period it was 3.8 years) ${ }^{9}$

Surely there is still the sole author who has invested a good deal of time in a research project, most likely the dissertation, that gets published in APSR. However, the emerging portrait of the profession that is visible from examining the APSR publications during the most recent 20 years conveys the image of a discipline comprised of small teams of collaborators, who most likely already have tenure, and who are working on fairly complex projects involving sophisticated methods and elaborate empirical evidence. This is a very different was evident 20 years ago. ${ }^{10}$

\section{Notes}

* This effort has been, perhaps more than anything else, an exercise in data set construction. We wish to thank those individuals whose countless hours of data collection, coding, and entry have made this article possible: Megan Lutz, Graham Fuller, Michelle Ucci, and Scott Fitzgerald. We also wish to thank Chia-Hsing Lu for technical assistance, Regan Chechhio for editorial assistance, and Peggy Swails for secretarial assistance.

1. This hypothesis is partly based on the findings of earlier research demonstrating a significant positive correlation between the prestige rating of journals and the Social Science Citations Index Impact Factor (Christenson and Sigelman 1985). The Impact Factor is a measure of the frequency with which the "average article" in a journal has been cited in a particular year. This earlier work was at the aggregate level, that is, at the level of the journal rather than at the level of the individual author. Nonetheless, it does suggest that if articles in more quently than those in less prestigious journals, then we should also expect that those authors who publish more frequently in the most prestigious journals should be cited relatively more often than those who publish less frequently. We are not aware, however, of any previous work examining this hypothesis at the individual level.

2. Of course we have no way to systematically control for authors who may have completely changed their names over the period examined. We were, however, able to account for authors who may have changed a single last name to a hyphenated name.

3. The 1994-96 APSA Directory of Members was used to locate information for autype of profession than that which prestigious journals are cited more fre- thors in the most recent 20 years, and the 1973 Directory of Members was used for those authors published in 1954-73. No other years' directories were used because of their scarcity. We are examining possible other sources of information to complete our data set.

4. Data were gathered from 1956 to 1975 for authors publishing between 1954 and 1973 and from 1971 to 1993 for authors publishing between 1974 to and 1994 because $\mathrm{SSCI}$ volumes are compiled in volumes from 1956-65, 1966-70, 1971-75, 1976-80, 1991, 1992 and 1993.

5. The first 49 years saw 25 authors with 10 or more publications in the APSR. This finding supports descriptions of the early $A P S R$ as a less prestigious journal where publication in the APSR did not carry the same noteworthiness that it does today.

6. This demonstrates that it would be very interesting to have data on the acceptance rates for those in the APSR Hall of Fame. Those data, however, are not available.

7. Since some articles were peer reviewed before 1967 (Patterson, Ripley, and Trish 1988, 20) we only note authors with publications before 1965. Riker had four publications before 1965, and W.E. Miller had four publications before 1965 .

8. Of course, one must be rather cautious in drawing this conclusion since the citation counts are affected by a number of problems that would tend to decrease this correlation. Moreover, there are interesting patterns of first authorship that can also influence this correlation because citation counts consider only first authors of multiple-authored articles. It is interesting to note that individuals who are frequently, but not always, the first author got higher numbers of citations on the average (893 lines of citations), than individuals who are always first authors (740 lines) during the most recent 20 years when collaboration has been increasing. Hence, collaborative work is certainly associated with higher citations than singleauthored work (even those individuals who are secondary authors on APSR articles receive relatively high numbers of citations, 487 lines on average). This relative high level of citing multiple-authored articles is interesting in its own regard, but it is also relevant here because rotating the first author on articles, something that happens frequently on collaborative work, has implications for using citations as the critical measure of performance and scholarly impact.

9. This difference may be slightly affected by a couple of interesting outliers that occur for the first 20 years. For example, 35 years elapsed between Lucien Pye's first and second APSR publication. His most recent $A P S R$ publication occurred in 1990 and was his APSA Presidential Address entitled, "Political Science and the Crisis of Authoritarianism." Also, 30 years elapsed between Herb Simon's first APSR publication and his revised James Madison Lecture entitled

"Human Nature in Politics: The Dialogue of Psychology with Political Science," which appeared in the June 1985 APSR. Removing these outliers actually has only an insignifi- 
cant impact on the difference between the mean time elapsed between the Ph.D. and first publication in the APSR for the first and second 20 -year period.

10. Of course a caveat is needed here. First of all, we are making generalizations about the profession from trends emerging in only five political science and one sociology journal. We have no evidence to indicate whether or not similar trends of increasing collaboration are appearing in other political science journals or in journals from other social science subfields such as anthropology or psychology. Nevertheless, if our explanation of the APSR trend is correct, then we would expect this trend to be visible in other political science journals, as well as the journals of other social science disciplines. Our future research plans include undertaking an analysis of yet other journals to determine if we have discovered a trend that appears in those journals as well. Until that work is complete, our results must be viewed as inconclusive. Secondly, the reader should be reminded that the data dealing with time of getting the $\mathrm{Ph}$.D. is still somewhat incomplete and as indicated earlier in the text is based upon a sample of 769 individuals out of the 1,628 authors. Given these limitations our conclusions must remain somewhat speculative.

\section{References}

Cnudde, Charles F. 1986. "Care in Using the Social Sciences Citation Index: Comment on Klingemann's Method." PS 19: 850-52.

Christenson, James A., and Lee Sigelman. 1985. "Accrediting Knowledge: Journal Stature and Citation Impact in Social Science." Social Science Quarterly 66: 964-76.

Festinger, L. 1954. "A Theory of Social Comparison Processes." Human Relations 7:117-40.

Garand, James C. 1990. "An Alternative Interpretation of Recent Political Science Journal Evaluations." PS 23:448-51.

Klingemann, Hans-Dieter. 1986. "Ranking the Graduate Departments in the 1980s: Toward Objective Qualitative Indicators." $P S$ 19:651-61.

Klingemann, Hans-Dieter, Bernard Grofman, and Janet Campagna. 1989. "The Political Science 400: Citations by Ph.D. Cohort and by Ph.D.-Granting Institution." PS 22:258-70.

Patterson, Samuel C., Brian D. Ripley, and Barbara Trish. 1988. "The American Po- litical Science Review: A Retrospective of the Last Year and the Last Eight Decades." PS 21:908-25.

Powell, G. Bingham, Jr. 1994. "Report of the Managing Editor of the American Political Science Review, 1993-94." PS 27:759-65.

Tajfel, Henri. 1981. Human Groups and Social Categories. Cambridge: Cambridge University Press.

\section{About the Authors}

Arthur H. Miller is professor of political science and director of the Iowa Social Science Institute at the University of Iowa.

Charles Tien is a Ph.D. candidate in political science at the University of Iowa. His dissertation research deals with presidential and congressional interactions in the federal budgetary process.

Andrew Peebler is a graduating senior in political science and an assistant study director in the Iowa Social Science Institute at the University of Iowa.

\title{
A Brief Citation Guide for Internet Sources in History and the Humanities (Version 2.0)
}

\author{
Melvin E. Page, $H$-Net and East Tennessee State University
}

The following suggestions for citations of Internet sources in history and the historically based humanities are derived from the essential principles of academic citation in Kate L. Turabian, A Manual for Writers of Term Papers, Theses, and Dissertations, 5th ed. (Chicago, University of Chicago Press, 1987). I have also drawn upon suggestions from some of the works listed below. The guide has been improved by the students of my Historical Methods classes at East Tennessee State University and my fellow H-AFRICA editors whom I thank for their assistance.

Since the Internet is an evolving institution, this guide is not intended to be definitive. Correc-

\footnotetext{
* Copyright Melvin E. Page, 1995. This document may be reproduced and redistributed, but only in its entirety and with full acknowledgment of its source and authorship.
}

tions, additions, comments, suggestions, and criticisms are therefore welcome. Please address them to the author at: <pagem@etsuarts. east-tenn-st.edu. $>$.

When the need for revisions and updates become apparent, new versions of the guide will be issued. The most recent version will be stored at the following URL, which is case sensitive: < gopher://h-net. msu.edu:70/00/lists/H-AFRICA/ internet-cit>.

\section{Bibliographic Citations}

\section{Basic Citation Components and Punctuation}

Author's Last Name, First Name. <author's internet address, if available $>$. "Title of Work" or "title line of message." In "Title of Complete Work" or title of list/site as appropriate. <internet address >. Date, if available.
The samples below indicate how citations of particular electronic sources might be made.

\section{Listserv Messages}

Walsh, Gretchen. <gwalsh@acs.bu.edu>. "REPLY: Using African newspapers in teaching." In H-AFRICA. $<$ h-africa@msu.edu>.18 October 1995.

\section{World Wide Web}

Limb, Peter. "Relationships between Labour \& African Nationalist/Liberation Movements in Southern Africa." $<$ http://neal.ctstateu.edu/history/ world_history/archives/limb-1.html>. May 1992.

\section{FTP Site}

Heinrich, Gregor. <100303.100@compuserve.com>. "Where There Is Beauty, There Is Hope: Sau Tome e Principe." <ftp.cs.ubc.ca/pub/local/ FAQ/african/gen/saoep.txt $>$. July 1994. 